\title{
Vertical Microscale Distribution of Phytoplankton in Relation to the Thermocline
}

\author{
J. B. Derenbach, H. Astheimer, H. P. Hansen and H. Leach \\ Institut für Meereskunde an der Universität Kiel, Düsternbrooker Weg 20, D-2300 Kiel 1, Federal Republic of Germany
}

ABSTRACT: Employing an in situ fluorometer, distinct chlorophyll maxima were measured within and below a seasonal thermocline in the Baltic Sea. At an average thickness of $34 \mathrm{~cm}$, these chlorophyll layers exceeded surface chlorophyll concentrations by a factor of between 8 to 10 . The average vertical distance between layers which contained four times the average concentration was found to be about $3.3 \mathrm{~m}$, horizontal extension some $10 \mathrm{~m}$. The chlorophyll layers are assumed to be a dynamic feature formed or maintained locally. A conceptual model is considered that might help to explain the mechanism.

\section{INTRODUCTION}

The observation of increased phytoplankton concentrations in and near the thermocline is by no means new. As long ago as 1948, Gessner reported on the vertical distribution of phytoplankton and the thermocline. With improved techniques for measuring chlorophyll making use of its in vivo fluorescence (Lorenzen, 1966), chlorophyll maxima were again detected in the thermocline (Lorenzen, 1967). Coupling the fluorimeter to a lowered pump (Strickland, 1968) enabled chlorophyll profiles to be obtained showing very distinct discontinuities. Mainly biological processes were considered to account for these phenomena. In earlier attempts, Steele (1964) and Bernhard and Rampsi (1965) had explained midwater chlorophyll maxima in biological terms. And still this is felt to be a challenge in the ecological puzzle (Fee, 1976). However, it is recognized that the structural properties of the habitat of plankton may well be more important than its population dynamics. This is, in fact, inherent in the definition of plankton.

Changes in the abundance of numerically dominant zoo- and phytoplankton species were measured by Cassie $(1959,1960)$ and found to correlate with changes in temperature and salinity. More general concepts of the organization of plankton were provided by Margalef (1967). Based on similar ideas, Richerson et. al. (1970) explained the paradox of plankton as a "contemporaneous disequilibrium". The existence of many patches of water is postulated; as each has different properties, competitive advantage is conferred on cer- tain plankton species. Platt (1972) actually compared the power spectral distribution of the chlorophyll concentration with physical properties of the mixed layer. The slope of the chlorophyll spectrum agreed with theoretical results published by Ozmidov (1965) for the kinetic energy distribution in the ocean over a wavelength band from $10^{-2}$ to $10^{6} \mathrm{~m}$. The concluding hypothesis is that local concentration of phytoplankton is largely controlled by turbulence, and not by dynamic attributes of the organisms.

This dominance of physical processes over biological and chemical factors in controlling phytoplankton variability could be further confirmed and seems to be established for events in the mesoscale range between 0.1 and $10 \mathrm{~km}$ in the ocean (Denman et al., 1977; Therriault et al., 1978; Therriault and Platt, 1978. The pattern is believed to be associated with the internal wave field (Platt and Denman, 1975). At scales below $100 \mathrm{~m}$ turbulent diffusion is thought to control phytoplankton patchiness (Platt and Denman, 1975; Richerson et al., 1975; Harris and Smith, 1977). Our measurements deal with these latter inhomogeneities in the vertical on a scale range well below $100 \mathrm{~m}$.

\section{MATERIAL AND METHODS}

Data were collected from stations in the Bornholm Basin (100-200 km NE and E of Bornholm; Baltic Sea) during the joint physical, chemical, and biological experiment Baltic ' 75 in May 1975. Cruise reports and data were published by Keunecke et al. (1975) and 
Kielmann et al. (1976). The ecological situation was characterized by Smetacek et al. (1978) in a report on the sedimentation of particulate matter during the phytoplankton spring bloom. With regard to our measurements, some additional data were collected in Kiel Bight during the summer of 1975 and 1976 in order to verify fluorometric results from the Bornholn Basin.

Chlorophyll profiles were measured with a modified Variosens fluorometer working at a pulse frequency of $6 \mathrm{~Hz}$. Properties of the instrument are discussed in detail by Herman (1975) and Herman and Denman (1977). Together with a diode-type thermometer both sensors were fastened $30 \mathrm{~cm}$ beneath the bottom of a profiler (containing current supply and recording units); thus they were assumed to measure undisturbed water. The sensors were set $10 \mathrm{~cm}$ apart but at the same level. The fluorimeter was focused to measure in vivo chlorophyll fluorescence in a volume of approximately $1 \mathrm{~cm}^{3}$. The profiler system was set up after learning of the microstructure apparatus used by Woods and Wiley (1972), and the same principle was employed to eliminate ship rolling motion by sliding the probe down a guide wire at an average terminal velocity of $15 \mathrm{~cm} \mathrm{~s}^{-1}$. However, when comparing temperature profiles from the chlorophyll probe with recordings from the Bathysonde, we recognized that this terminal sinking velocity was not immediately reached after starting the probe due to minor ship movements.

Each of the signals obtained was taken to control frequencies of a function generator resulting in frequency shifts, the attenuated sine wave output being stored on a two channel tape recorder. For further processing the frequency-analogue signals were demodulated, passed through a low-pass filter, and digitised at a sampling rate of $128 \mathrm{~s}^{-1}$. When plotting these raw data, each fluorescence signal appeared as maximum at the pulse frequency of $6 \mathrm{~Hz}$. This cyclic noise was corrected by selecting the local maxima and averaging every 6 neighbouring maxima. These data were obtained at one second intervals. When in a preliminary test run fluorometer signals were triggered at frequencies between 0.4 to $6 \mathrm{~Hz}$, the average of each 6 following peaks was found to vary by $\pm 18 \%$.

The in vivo fluorescence signal was calibrated by comparing average recordings (from depths between 4-10 m) with discrete chlorophyll a measurements (v. Bröckel, unpublished; analysis according to UNESCO, 1966, and Derenbach, 1969) from water samples at different stations taken parallel to our sampling. The scattering of these data was to some extent corrected for by the assumption that the calibration curve would be similar in shape to a calibration curve provided by the manufacturer of the fluorometer which was obtained using crystalline chlorophyll from spinach (Fig. 1).

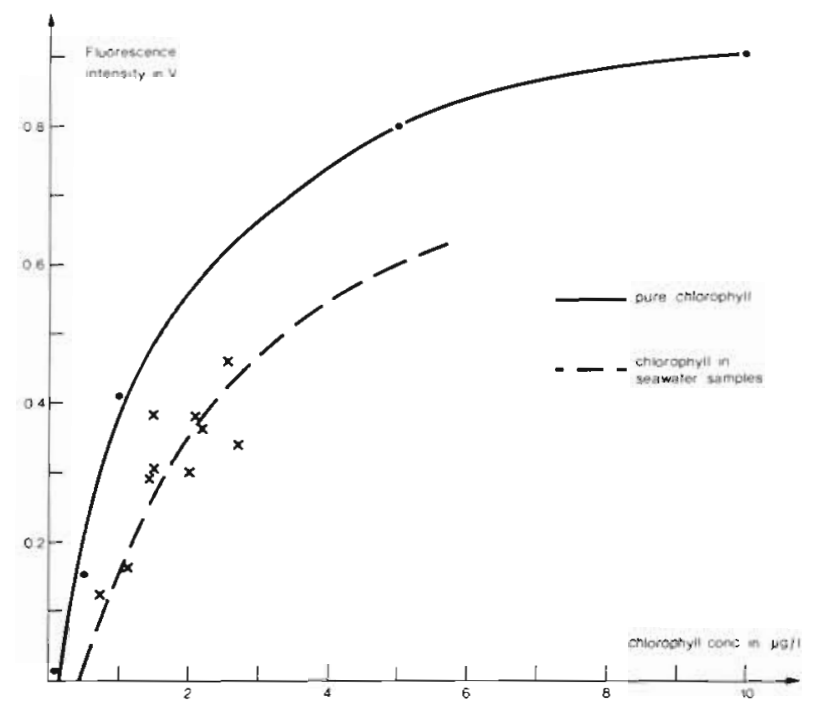

Fig. 1. Calibration curve of the in-vivo fluorescence signal. Averaged in situ fluorometer recordings from surface water in different areas are plotted versus single photometric chlorophyll a measurements from water bottles. The calibration curve is shaped according to measurements obtained with crystalline chlorophyll

\section{RESULTS AND DISCUSSION}

A characteristic chlorophyll-temperature profile is given in Figure 2 (Station No. 244). As a general feature there is a drastic increase in the variability of fluorimetrically measured chlorophyll with depth. In the upper layer the average chlorophyll concentration is at $1.7 \mu \mathrm{g} \mathrm{dm}^{-3}$ with a standard deviation of $\pm 0.2 \mu \mathrm{g} \mathrm{dm}^{-3}$. Within the thermocline the standard deviation goes up to $\pm 0.9 \mu \mathrm{g} \mathrm{dm}^{-3}$ at a chlorophyll level of $1.5 \mu \mathrm{g} \mathrm{dm}^{-3}$. The decline in the average chlorophyll concentration with depth, as measured by our instrument, is not so pronounced as that measured with the conventional photometric technique in samples taken from water bottles. This is perhaps due to physiological changes in the phytoplankton caused by changes in environmental parameters resulting in a stimulation or suppression of chlorophyll fluorescence (Kiefer, 1973). With regard to the rather uniform phytoplankton population, in which Skeletonema costatum is by far the most dominant organism (Smetacek et al., 1978), the order of magnitude for these changes is thought to be below a factor of 1.5 .

Some more profiles are given in Figure 3. The results from measurements at Stations No. 240, 243, $245,246,247$ were in principle similar to those of the previous one - all these stations being about 70 to $110 \mathrm{~km}$ NE of Bornholm. The average variability (given as standard deviation) of chlorophyll at all stations was found to be $\pm 0.2 \mu \mathrm{g} \mathrm{dm}^{-3}( \pm 12 \%)$ in the 


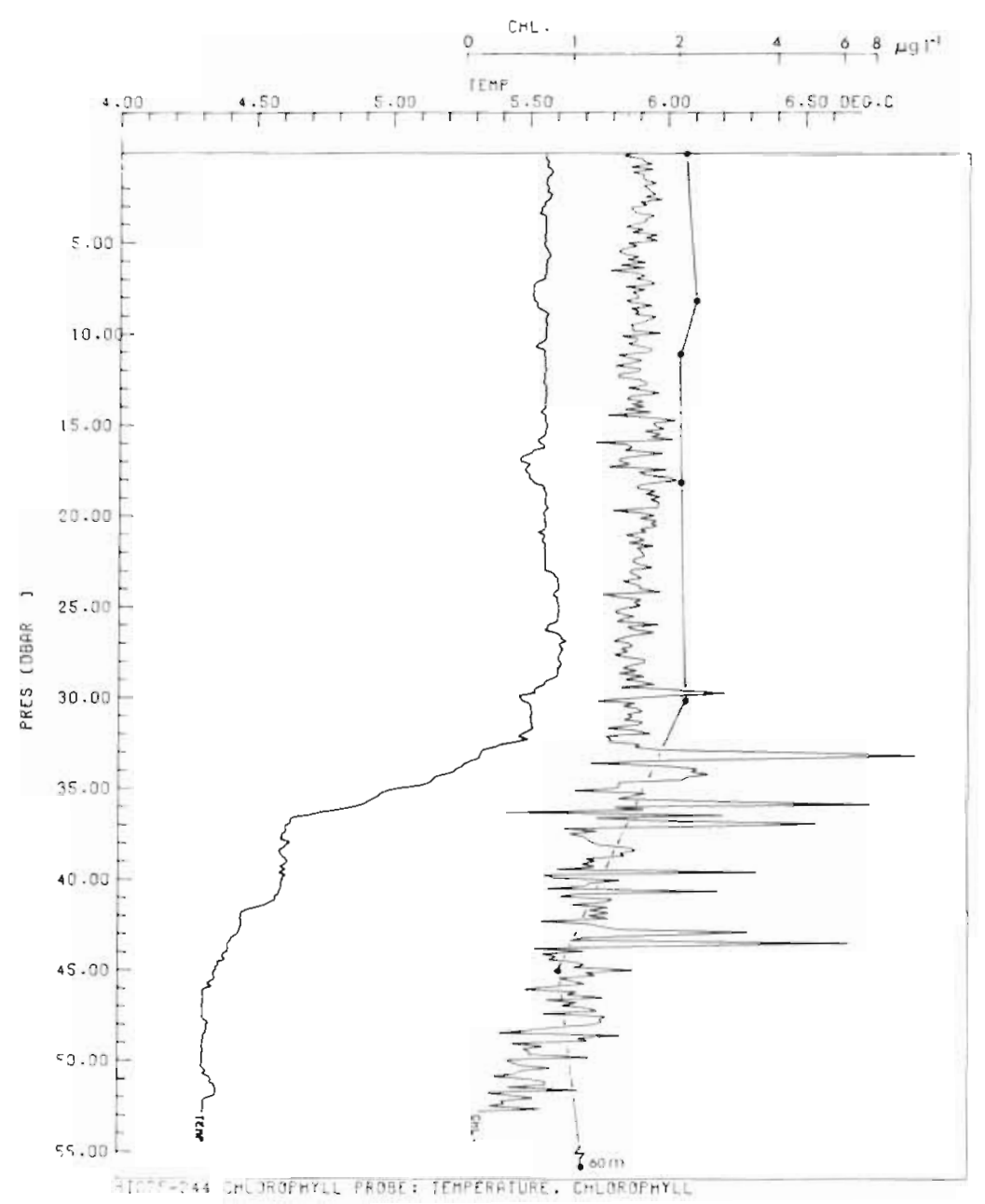

Fig. 2. Chlorophyll and temperature profile from Station No. 244. The discrete measurements are photometrically determined chlorophyll a concentrations from water bottles

upper layer and $\pm 1.1 \mu \mathrm{g} \mathrm{dm}^{-3}( \pm 71 \%)$ within and below the thermocline. The average thickness of distinct chlorophyll layers was measured to be $34 \mathrm{~cm}$ $( \pm 13 \mathrm{~cm}$ ) with a chlorophyll concentration around 8 to 10 times the average concentration in the thermocline and at times even rising to more than 20 times this average value. However, on two occasions only, at Stations No. 239 and 259, chlorophyll a concentrations in water bottles from greater depths were found to be twice the average concentration of the surface layer.

Further east, 110 to $300 \mathrm{~km}$ east of Bornholm, at stations with a less developed thermocline (e. g. Stations No. 250, 251, 255), hardly any structure in the distribution of chlorophyll could be detected. This was probably due to the premature state of development of the spring phytoplankton bloom and of the thermocline. Later measurements were repeated in Kiel Bight during the summer of 1975 and 1976. Again profiles with distinct chlorophyll layers were obtained. Here the opportunity was taken to take repeated measure- ments in series in order to gain some information on horizontal dimensions of chlorophyll layers. During scuba dives at Boknis Eck (Kiel Bight) some visual observations of layers containing high concentrations of particulate matter had already been made (Black, Ehrhardt, personal communication). These layers were found to have a thickness of some centimetres to a few decimetres and extended horizontally for at least some $10 \mathrm{~m}$. Similar observations had been reported by Lenz (1965), when working on sound-scattering layers. Measurements with the chlorophyll profiler at horizontal distances of about 10 to $20 \mathrm{~m}$ revealed similar patterns in the general chlorophyll distribution, whereas individual peaks vanished, or separated into two, or merged. Hence the horizontal extension of individual layers seems to be in the order of magnitude of some $10 \mathrm{~m}$ only.

Summarizing the visual inspection of profiles sampled, a drastic increase in the variability of chlorophyll is observed below the upper mixed layer, that is in and 
below the thermocline. Here chlorophyll profiles resemble temperature microstructure plotted as temperature gradient as it was found by Woods and Wiley (1972) and Kullenberg (1974). When first measuring the chlorophyll we had hoped to find some coincidence of features between temperature microstructure and chlorophyll distribution. However, this striking similarity came as a surprise, since processes that lead to thermal stratification of water masses do not necessarily also lead to a stratification of particulate matter other than perhaps reflecting the origin of layers present in the thermocline. Only when a certain degree of stratification is reached, does particulate matter seem to be significantly affected in its tendency to fall through the water column once it is lost from the more general mixed surface layer and in spite of the struggle of its living fraction to remain suspended.
An initial conclusion is drawn from maximum chlorophyll concentrations in some of the more pronounced chlorophyll layers. Since concentrations here were found to exceed surface chlorophyll concentrations by an order of magnitude, an explanation would not be transport of surface water into the thermocline. Rather one is led to believe in some accumulating processes in certain layers of the thermocline, e.g. where differences in intensity of turbulence would considerably slow down the sedimentation of phytoplankton (and particles of similar size) below the upper surface water. Some effects of turbulence on the sinking behaviour of phytoplankton are discussed by Smayda (1970) and Margalef (1975).

An indication to support our idea of a delay in the sinking of phytoplankton by turbulence is derived from size and concentration of chlorophyll in
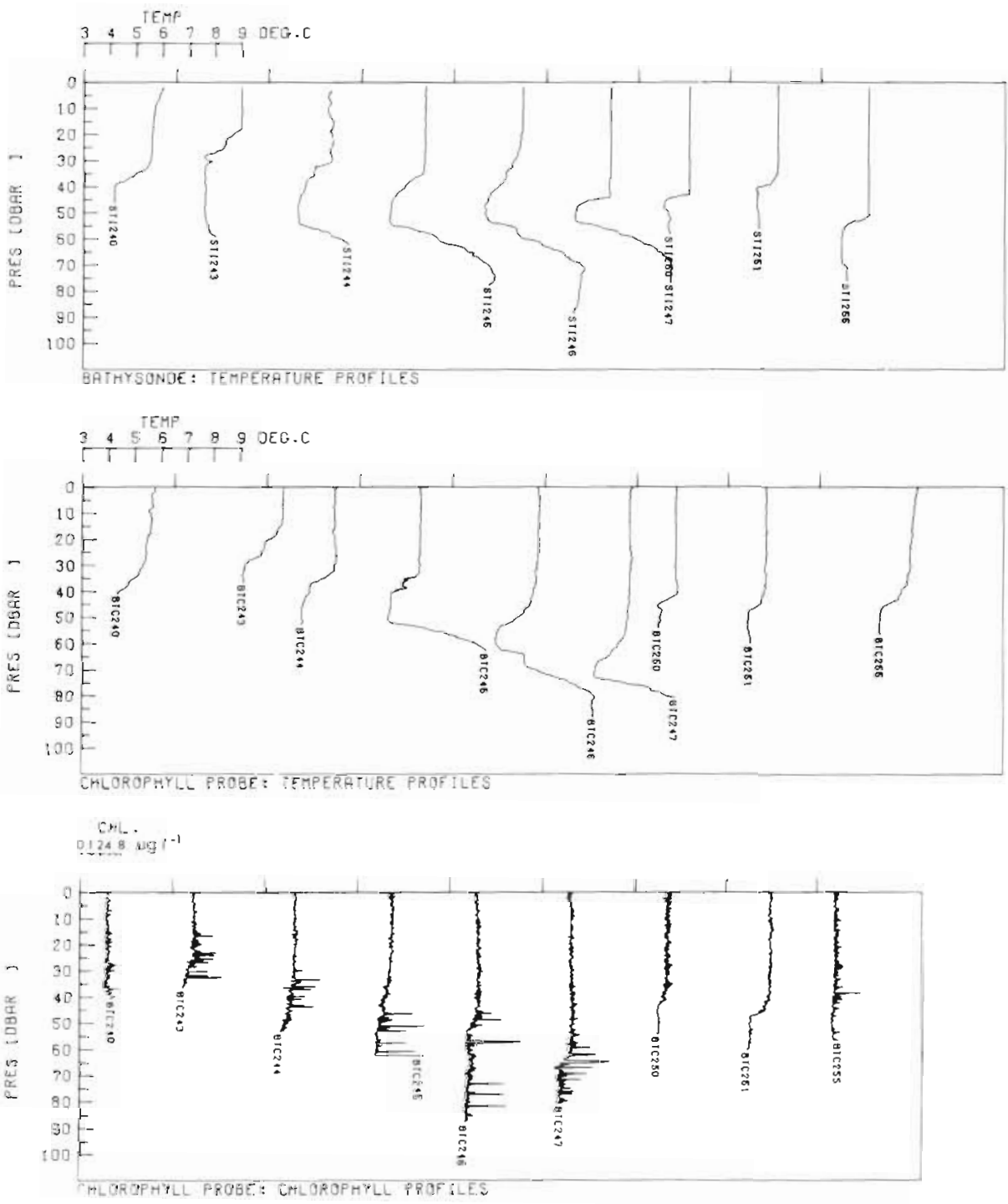

Fig. 3. Temperature profiles from the Bathysonde and temperature and chlorophyll profiles from the fluorometer 
chlorophyll layers and their distance to neighbouring layers. Taking the observed average thickness of chlorophyll layers of $34 \mathrm{~cm}$ at a chlorophyll concentration of ten times the average value, one would expect an average distance of $3.4 \mathrm{~m}$ as a 'nonturbulent' intermediate layer between chlorophyll layers to sample phytoplankton from. Actually measured was an average distance of 3.3 ( \pm 3.2 ) $\mathrm{m}$ between chlorophyll layers which contained more than four times the average concentration of chlorophyll. This large standard deviation may reflect the differences in concentrations (4-20fold the average) or indicate different stages of the development of chlorophyll layers.

Knowing something about average vertical dimensions of chlorophyll layers, one is tempted to speculate on their lifetime. At least a minimum lifetime may be calculated from sinking velocities of phytoplankton. The time necessary for phytoplankton to accumulate from the separating layers into chlorophyll layers to reach about the above-mentioned tenfold concentration is thought to be equal to a minimum lifetime of a chlorophyll layer. Calculating from maximum sinking velocities of $40 \mathrm{~m} \mathrm{day}^{-1}$ - reported for some diatoms (Smayda and Boleyn, 1965) and for small particulate faecal material (Bishop et al., 1978) - a minimum lifetime would not be shorter than about $2 \mathrm{~h}$. However, on the average sinking rates may be expected to be considerably smaller (Margalef, 1961). The sinking rates of Skeletonema costatum, the dominant phytoplankton organism at that time in the Bornholm Basin, can be expected to range from 0.30 to $1.35 \mathrm{~m} \mathrm{day}^{-1}$ (Smayda and Boleyn, 1966). Thus, the residence time of an individual organism within a chlorophyll layer could be as much as $2.5 \mathrm{~d}$. This would be an order of magnitude of much more ecological consequence as compared to a lifetime of a few hours only.

The limited number of measurements has hampered a more detailed analysis of data. A cross-correlation and a spectral analysis did not provide significant information. However, we now consider a simple conceptual model that might help to explain the mechanism of chlorophyll layer formation.

As concluded above, it is very unlikely that the inhomogeneities in the phytoplankton distribution simply indicate water masses of different origin, since maximum chlorophyll concentrations observed in the thermocline vastly exceed those measured in the surface water either locally or further afield (e.g. Smetacek et al., 1978). This would tend to imply that the chlorophyll layers are a dynamic feature being formed or maintained locally and the concept we should consider is a model of the downward flux of the phytoplankton

In a simple mathematical approach we will start with the continuity equation (Landau and Lifshitz, 1959)

$$
\frac{\partial c}{\partial t}=-\operatorname{div}(c \mathbf{u})
$$

where the left hand side represents the time-rate-ofchange of density of material and the right hand side the divergence of material. The vector $\mathbf{u}=(u, v, w)$ represents the three dimensional flux of material and the scalar $c$ is its concentration. This equation as it appears here also assumes there are no sources or sinks of material. In our case, we can for the time being reasonably assume there is little phytoplankton being formed well down in the thermocline.

It is now pertinent to consider the relationship between the phytoplankton flux and the fluid dynamics of the thermocline. In our model we represent only the net flux of the plankton and not its explicit motions. Crucial to the model is that the net downward flux (sedimentation rate, $w$ ) of the phytoplankton is nonhomogeneous as a result of complicated (quasi-twodimensional) flows within the thermocline producing layers of increased turbulence activity there (Woods and Wiley, 1972). So long as this activity somehow causes $w$ to be a function of $z$ (the vertical co-ordinate), then the concentration can also be expected to be a function of $z$. To show formally how this vertically variable net sedimentation rate affects the concentration, we consider our ocean to be horizontally uniform $(\partial / \partial x=\delta / \partial y=0)$ and steady state $(\delta / \partial t=0)$. Admittedly, in practice these assumptions are not satisfactory but in deference to Ockham's principle it is necessary to consider the simplest one-dimensional case first. Applying these assumptions to the Equation (1) produces

$$
\frac{d}{d z}(c w)=0
$$

which can be integrated to give

or

$$
c w=\text { constant }
$$

$$
c \propto \frac{1}{W}
$$

Verbally, the concentration is inversely proportional to the net downward flux; where the net sedimentation rate is small the concentration is large and vice versa. According to this concept the observed layers with high chlorophyll concentration correspond to layers in which the net downward motion of the phytoplanktion is relatively small, an order of magnitude smaller perhaps, due to turbulent activity. We illustrate our model in Figure 4, where $w$ is taken to be a simple function of $z$ with a minimum at a level, $z=0$, and tending to unity at infinity; $c$ is consequently modelled so that its value is unity at infinity and maximum at $z=o$.

We freely admit that our model is very simple, neglects many important complicating effects and 


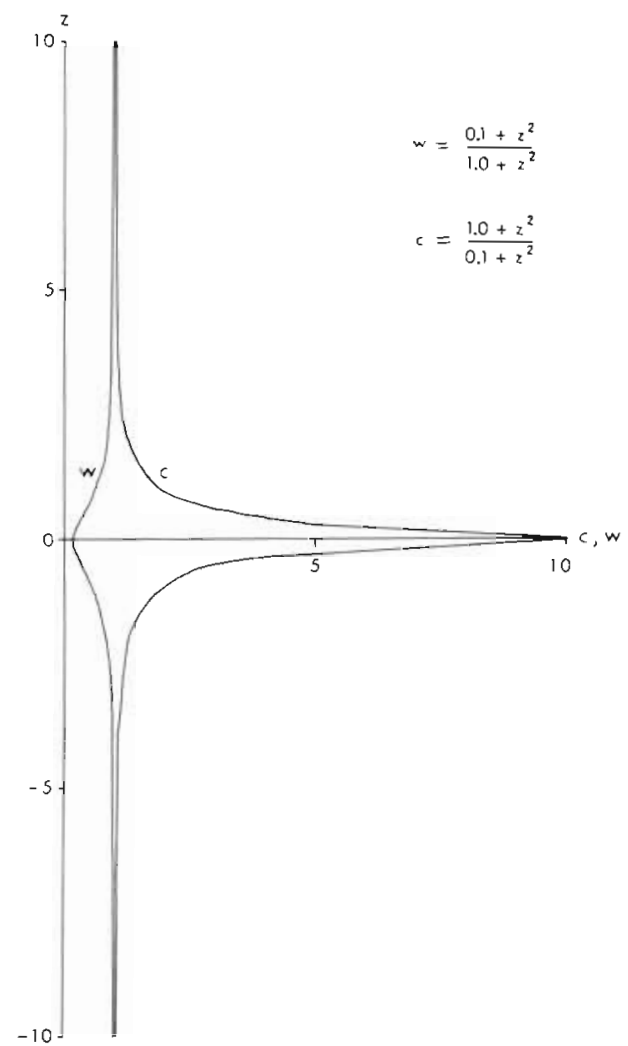

Fig. 4. Curves to illustrate the model of phytoplankton downward flux leading to chlorophyll layers. The concentration (c) of plankton is set equal to $1 / w$, where $w$ is the net downward flux of phytoplankton. The mathematical functions used for the curves are arbitrary as are the units

depends crucially on how the microscale turbulence within the thermocline affects the net downward flux of the phytoplankton; however, we consider that nevertheless the principal physics of the formation of the observed chlorophyll layers may possibly be explained in this way.

Acknowledgements. This study was supported by the Deutsche Forschungsgemeinschaft. We are indepted to Professor K. Grasshoff, chief scientist on the R. V 'Meteor' cruise Baltic 1975. We should also very much like to thank friends in almost every department of our institute for their support.

\section{LITERATURE CITED}

Bernhard, M. and Rampsi, L. (1965). Horizontal microdistribution of marine phytoplankton in the Ligurian Sea. Bot. Gothoburg., 3, 13-24.

Bishop, J. K. B., Ketten, D. R. and Edmond, J. M. (1978). The chemistry, biology and vertical flux of particulate matter from the upper $400 \mathrm{~m}$ of the Cape Basin in the southeast Atlantic Ocean. Deep Sea Res., 25, 1121-1161

Cassie, R. M. (1959). Microdistribution of plankton. N. Z. Jl Sci., 2, 398-409.
Cassie, R. M. (1960). Factors influencing the distribution of plankton in the mixing zone between oceanic and harbour waters. N. Z. Jl Sci., 3, 26-50.

Denman, K., Okubo, A and Platt, T (1977). The chlorophyll fluctuation spectrum in the sea. Limnol. Oceanogr., 22, 1033-1038.

Derenbach, J. (1969). Zur Homogenisation des Phytoplanktons für die Chlorophyllbestimmung. Kieler Meeresforsch., 25, 166-171.

Fee, E. J. (1976). The vertical and seasonal distribution of chlorophyll in lakes of the Experimental Lake Area, NW Ontario: Implications for primary production estimates. Limnol. Oceanogr., 21, 767-783.

Gessner, F. (1948). The vertical distribution of the phytoplankton and the thermocline. Ecology, 29, 386-389.

Harris, G. P. and Smith, R. E. H. (1977). Observations of small-scale spatial patterns in phytoplankton populations. Limnol. Oceanogr., 22, 887-899.

Herman, A. W. (1975). Chlorophyll and dye detection with the variosens fluorometer. Bedford Inst. Oceanogr. Rep. Ser, $B I-R-75-2,1-37$.

Herman, A. W. and Denman, K. L. (1977). Rapid underwater profiling of chlorophyll with an in situ fluorometer mounted on a 'Batfish' vehicle. Deep Sea Res., 24, 385-397.

Keunecke, K. H., Kohn, H., Krauss, W., Miosga, G., Schott, F., Speth, P., Willebrand, J. and Zenk, W. (1975). Baltic '75physikalischer Teil -, Messungen des I.f.M., der F.W.G. und der D.F.U.L.R. Ber. Inst. Meeresk. Kiel, 11, 1-100.

Kiefer, D. A. (1973). Chlorophyll a fluorescence in marine centric diatoms: response of chloroplasts to light and nutrient stress. Mar. Biol., 23, 39-46.

Kielmann, J., Holtorf, J. and Reimer, U. (1976). Data Report Baltic 75. Ber. Inst. Meeresk. Kiel, 26, 1-155.

Kullenberg, G. (1974). Investigation of small-scale vertical mixing in relation to the temperature structure in stably stratified waters. Adv. Geophys., 18 A, 339-351.

Landau, L. D. and Lifshitz, E. M. (1959). Fluid Mechanics, Vol. 6, Pergamon Press, Oxford.

Lenz, J. (1965). Zur Ursache der an die Sprungschicht gebundenen Echostreuschichten in der westlichen Ostsee. Ber dt. wiss. Kommn Meeresforsch., 18, 111-161.

Lorenzen, C. J. (1965). A method for the continuous measurement of in vivo chlorophyll concentration. Deep Sea Res., $13,223-227$.

Lorenzen, C. J. (1967). Vertical distribution of chlorophyll and phaeopigments: Baja California. Deep Sea Res., 14, 735-745.

Margalef, R. (1961). Velocidad de sedimentación de organismos pasivos de fitoplancton. Investigación pesq., 18, 3-8.

Margalef, R. (1967). Some concepts relative to the organization of plankton. Oceanogr. mar Biol., 5, 257-289.

Margalef, R. (1975). Phytoplankton communities in upwelling areas. The example of NW-Afrika. In International Symposium on Upwelling Ecosystems, Kiel.

Ozmidov, R. V (1965). Energy distribution between oceanic motions of different scales. (Engl. transl.) Am. Geophys. Union, Izvestiya, Atmosph. Ocean. Phys., 1, 257-261.

Platt, T. (1972). Local phytoplankton abundance and turbulence. Deep Sea Res., 19, 183-187

Platt, T, and Denman, K. L. (1975). Spectral analysis in ecology. A. Rev. ecol. Syst, 6, 189-210.

Richerson, P., Armstrong, R. and Goldman, C. R. (1970). Contemporaneous disequilibrium, a new hypothesis to explain the 'paradox of plankton' Proc natn. Acad. Sci. U.S.A., 67, 1710-1714.

Richerson, P. J., Dozier, B. J. and Maeda, B. I (1975). The structure of phytoplankton associations in Lake Tahoe 
(California-Nevada). Verh. int. Verein theor angew. Limnol., 19, 843-849.

Smayda, T J. (1970). The suspension and sinking of phytoplankton in the sea. Oceanogr. mar. Biol., 8, 353-414.

Smayda, T. J. and Boleyn, B. J. (1965). Experimental observations on the flotation of marine diatoms. I. Thalassiosira c. f. nana, Thalassiosira rotula and Nitzschia seriata. Limnol. Oceanogr., 10, 499-509

Smayda, T J. and Boleyn, B. J. (1966). Experimental observations on the flotation of marine diatoms. II. Skeletonema costatum and Rhizosolenia setigera. Limnol. Oceanogr., $11,18-34$.

Smetacek, V., Bröckel, K. v., Zeitzschel, B. and Zenk, W. (1978). Sedimentation of particulate matter during a phytoplankton spring bloom in relation to the hydrographic regime. Mar. Biol., 47, 211-226.

Steele, J. H. (1964). A study of production in the Gulf of Mexico. J. mar. Res., 22, 211-222.
Strickland, J. D. H. (1968). A comparison of profiles of nutrient and chlorophyll concentrations taken from discrete depths and by continuous recording. Limnol. Oceanogr., 13, 388-391.

Therriault, J.-C. and Platt, T (1978). Spatial heterogeneity of phytoplankton biomass and related factors in the nearsurface waters of an exposed coastal embayment. Limnol. Oceanogr., 23, 888-899.

Therriault, J.-C., Lawrence, D. J. and Platt, T. (1978). Spatial variability of phytoplankton turnover in relation to physical processes in a coastal environment. Limnol. Oceanogr., 23, 900-911

Unesco (1966). Determination of photosynthetic pigments in seawater. Monogr. Oceanogr. Methodol, 1, 1-66.

Woods, J. D. and Wiley, R. L. (1972). Billow turbulence and Ocean microstructure. Deep Sea Res., 19, 87-121.

This paper was submitted to the editor; it was accepted for printing on September 7, 1979. 